\title{
Experimental Investigations to Study the Air Flow Patterns on the Headlight Domes of Different Two Wheelers
}

\author{
Samadhanam Raju K*, Subhakanth P**, Mr. P.V.S. Murali Krishna*** \\ *(Asst. Professor, Department of Mechanical Engineering, Pydah College of Engineering \& Technology, \\ Visakhapatnam, India \\ ** (PG Student, Department of Mechanical Engineering, NSRIT, Visakhapatnam, India \\ *** (Assoc. Professor and Head of the Department, Mechanical Engineering, NSRIT, Visakhapatnam, India
}

\begin{abstract}
This paper presents some experimental investigations to study the air flow patterns on the headlight domes of different two wheelers (HERO HONDA PASSION PLUS and BAJAJ PULSAR) which influence the stability of the vehicle. The pressure distribution over the surface of the profile and the drag force are to be determined for various headlight dome orientations. This study helps in suggesting the suitable headlight dome profile that may reduce the drag force and effect of turbulence which in turn leads to the increase of vehicle stability. The results obtained during the simulation are to be validated by conducting the experiments on the scale down model of the headlight dome of HERO HONDA PASSION PLUS using Wind Tunnel test rig. The Computational Fluid Dynamics (CFD) tool was used to simulate the air flow pattern on the headlight dome in which boundary layer separation doesn't exist. The results obtained from the simulation are to be compared with the experimental results from the wind tunnel and the variation is to be found and that should be in the acceptable limit.
\end{abstract}

Keywords: Drag force, Pressure distribution, Wind tunnel, Simu lation, Velocity, Adverse pressure gradient, Boundary layer separation.

\section{INTRODUCTION}

In present days, people are using the motor bikes with different types of headlight domes. This study explains the importance of the air flow pattern on the headlight domes of different bikes using CFD simulation and experimental validation. Wind tunnel was used to validate the simulation results. This study may helpful in view of vehicle stability and fuel efficiency. This will reduce the load on the handle bar of the vehicle which will increase the stability of the vehicle on the road. This paper was proposed to carry out the study of air flow pattem on the profile of the headlight domes of two bikes namely HERO HONDA PASSION PLUS and BAJAJ PULSAR in view of pressure distribution and drag force for various orientations of the dome. And also this includes the validation for HERO HONDA PASSION PLUS dome using wind tunnel which is a device for producing air flow relative to the body under test. In order to simulate the air flow pattern, Computational Fluid Dynamics was used. This method is mainly used to solve the problems such as numerical simulation of aerodynamic profiles, the admission and flow of gas mixture in engines and so on. This has been done for a particular position of the headlight dome and for a given velocity of air flow.

In some research journals, they perform the CFD simulation for flow over passenger car using two tail plates for aero dynamic drag reduction and so fuel economy [1]. And also the simulation analysis of aerodynamic characteristics of different two dimensional automobile shapes [4] and the objective of which was to obtain the distribution of air pressure and air flow vector variation. But the present study is concerning about the drag and pressure distribution over the surface of the profile of the headlight dome at a particular position and for a given speed of wind flow in which boundary layer separation does not exist to increase the vehicle stability and optimize the fuel efficiency. In order to optimise the air flow pattern over the surface of the profile of the headlight domes of the motor bikes (HERO HONDA PASSION PLUS and BAJAJ PULSAR), the pressure distribution and the effect of drag over the profile are to be analyzed for different orientations of the headlight domes such that $0^{\circ}, 5^{\circ}$ $(+\mathrm{Z}), 10^{\circ}(+\mathrm{Z}), 15^{\circ}(+\mathrm{Z}), 5^{\circ}(-\mathrm{Z}), 10^{\circ}(-\mathrm{Z}), 15^{\circ}(-\mathrm{Z})$ for HERO HONDA PASSION PLUS DOME and $0^{\circ}$, $5^{\circ}(+\mathrm{Z}), \quad 10^{\circ}(+\mathrm{Z}), 15^{\circ}(+\mathrm{Z}), \quad 20^{\circ}(+\mathrm{Z}), 25^{\circ}(+\mathrm{Z})$ for BAJAJ PULSAR DOME. In both these two domes, the reference dome position is not the same. In this study the air flow direction is in $\mathrm{Z}$ direction. By varying the positions of the headlight dome about $X$ axis through a $5^{\circ}$ step and the air flow pattern in terms of pressure distribution and drag force is to be studied. 


\section{GEOMETRY CREATION}

The geometries of the headlight domes of HERO HONDA PASSION PLUS (a) and BAJAJ PULSAR (b) have shown in the figure 1. These were created in the ICEM CFD software by taking the dimensions of the headlight domes in $\mathrm{X}, \mathrm{Y}$ and $\mathrm{Z}$ directions. The geometry creation [5] was carried out through the steps like creation of points, creation of lines or curves, creation of surfaces. After the creation of geometry, it was imported to the Ansys workbench design modeler in which the domain was created around the profile of the headlight dome of a two wheeler. In this design modeler, scaling has to be given to the profile in order to validate the simulation with the experimentation using wind tunnel. The model which was created in the ICEM CFD should be scaled down to satisfy the requirements of the dimensions of the wind tunnel which is a suction type and open circuit wind tunnel.

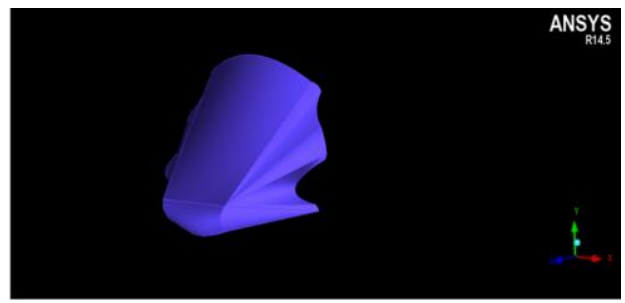

(a) Hero Honda passion plus dome.

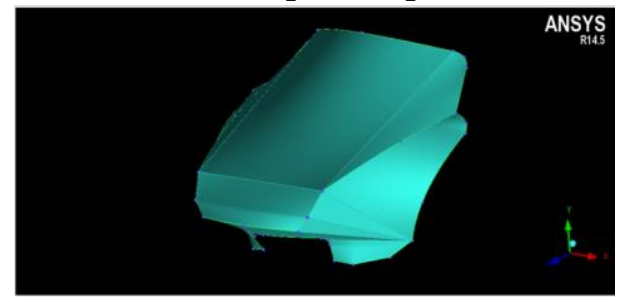

(b) Bajaj Pulsar dome.

Fig. 1. Geo metries of headlight domes.

Scaling factor for Hero Honda passion plus profile, S.F $=0.005$

Scaling factor for Bajaj Pulsar profile, S.F $=0.0045$

For experimental validation, the surface area of the test section of wind tunnel was considered to be $900 \mathrm{~cm}^{2}$.

Drag force can be calculated as;

Drag force $=$ average pressure obtained $*$ surface area
Table 1: S.F's for Hero Honda dome.

\begin{tabular}{|c|c|c|c|c|c|}
\hline $\begin{array}{l}\text { Angular } \\
\text { position }\end{array}$ & $\begin{array}{l}\text { S.F for } \\
\text { Domain }\end{array}$ & $\begin{array}{c}\text { Effecti } \\
\text { ve } \\
\text { Area } \\
\text { (sq.cm) }\end{array}$ & $\begin{array}{l}\text { Angular } \\
\text { position }\end{array}$ & $\begin{array}{l}\text { S.F for } \\
\text { Domain }\end{array}$ & $\begin{array}{c}\text { Effective } \\
\text { Area } \\
\text { (sq.cm) }\end{array}$ \\
\hline \multirow{2}{*}{$\begin{array}{c}0^{\circ} \\
\text { (reference) }\end{array}$} & \multirow[t]{2}{*}{0.6525} & \multirow[t]{2}{*}{900.76} & & & \\
\hline & & & $0^{\circ}$ (reference) & 0.678 & 900.43 \\
\hline $5^{\circ}(+Z)$ & 0.6475 & 900.8 & $5^{\circ}(+Z)$ & 0.673 & 900.02 \\
\hline $10^{\circ}(+Z)$ & 0.6434 & 900.71 & $10^{\circ}(+Z)$ & 0.669 & 900.05 \\
\hline $15^{\circ}(+Z)$ & 0.6402 & 900.54 & $15^{\circ}(+Z)$ & 0.666 & 900.56 \\
\hline $5^{\circ}(-Z)$ & 0.6585 & 900.78 & $20^{\circ}(-Z)$ & 0.6635 & 900.24 \\
\hline $10^{\circ}(-Z)$ & 0.6655 & 900.8 & & & \\
\hline $15^{\circ}(-Z)$ & 0.6696 & 900.09 & $25^{\circ}(-Z)$ & 0.662 & 900.45 \\
\hline
\end{tabular}

\section{MESH GENERATION}

Basically simulation in CFD can be performed in these following steps such as geometry creation, mesh generation, pre-processing, solving and post-processing. For mesh generation, in details of mesh, the relevance centre of sizing was taken as fine and the method of assembly meshing was taken as tetrahedrons. The mesh generation for both the domes shown in figure 2 and in wire frame model.

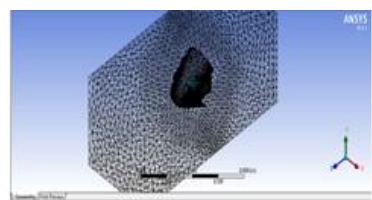

(a) Meshing of Hero Honda dome.

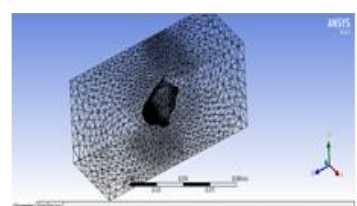

(b) Meshing of Bajaj Pulsar dome.
Fig. 2. Meshing of headlight domes.

In pre-processing, material properties and boundary conditions have to be given to perform the solution in FLUENT.

Boundary conditions:

Inlet condition: velocity $(21.36 \mathrm{~m} / \mathrm{s})$

Outlet condition: pressure $(0 \mathrm{~Pa})$

Wall condition: stationary and no slip

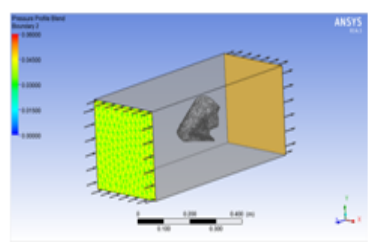

(a) Boundaries ofHero Honda dome.

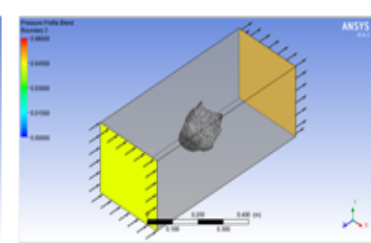

(b) Boundaries of Bajaj Pulsar dome.

Fig. 3. Boundaries of headlight domes.

The figure 3 shows that the model with boundaries. 


\section{SIMULATION}

For HERO HONDA passion plus dome:

The simulation was carried out in the FLUENT.

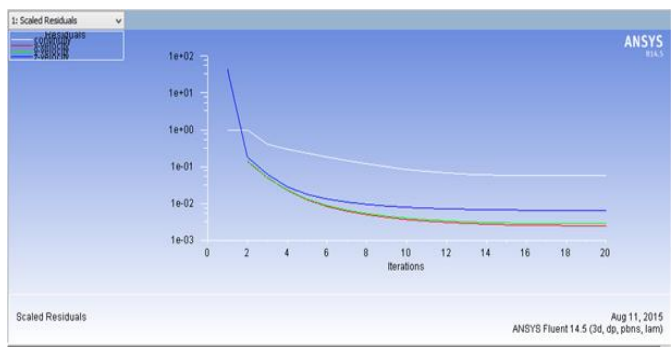

Fig. 4. Solution of Hero Honda dome.

The above figure 4 shows that the scaled residuals of continuity, $\mathrm{x}$-momentum, $\mathrm{y}$-momentum and $\mathrm{z}$-momentum. At the end of each solver iteration, the residual sum for each of the conserved variables is computed and stored, thereby recording the convergence history. This history is also saved in the data file. On a computer with infinite precision, these residuals will go to zero as the solution converges.

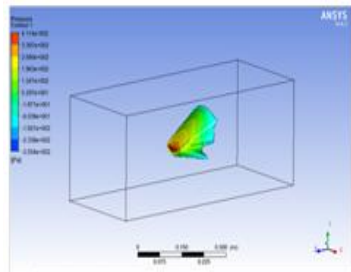

(a) Pressure distribution.

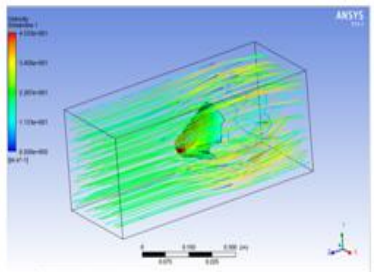

(b) Stream lines.
Fig. 5. Pressure distribution and Stream lines for Hero Honda dome.

Pressure Distribution in $\mathrm{Pa}$ :

411.4, 339.7, 268.0, 196.3, 124.7, 52.97, -18.71, $90.39,-162.1,-233.8,-305.4$

Average Static Pressure Obtained, $\mathrm{P}=-200.31 \mathrm{~Pa}$.

Drag obtained, $\mathrm{F}=-200.31 * 900.76^{*} 10^{\wedge}-4$

$$
=-18.04 \mathrm{~N}
$$

Check for boundary layer separation:

Flow separation occurs when the boundary layer travels far enough against an adverse pressure gradient $[(\partial \mathrm{P} / \partial \mathrm{x})>0]$ that the speed of the boundary layer relative to the object falls almost to zero. The fluid flow becomes detached from the surface of the object, and instead takes the forms of eddies and vortices.

From the pressure distribution, $(\partial \mathrm{P} / \partial \mathrm{x})$ is less than zero and so boundary layer separation does not exist at this particular velocity.

\section{For B ajaj Pulsar dome:}

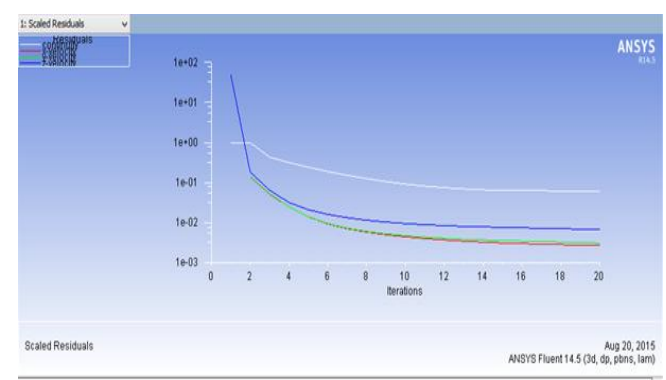

Fig. 6. Solution of Bajaj Pu lsar dome.

The above figure 6 shows that the scaled residuals of continuity, $\mathrm{x}$-momentum, $\mathrm{y}$-momentum and $\mathrm{z}$ momentum. At the end of each solver iteration, the residual sum for each of the conserved variables is computed and stored, thereby recording the convergence history.

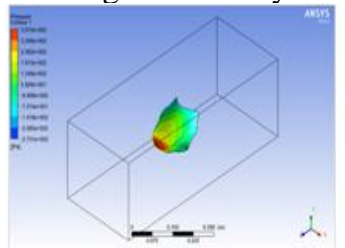

(a) Pressure distribution.

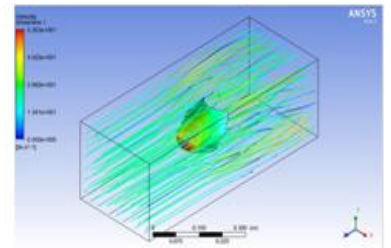

(b) Stream lines.
Fig. 7. Pressure distribution and Stream lines for Bajaj Pulsar dome.

Pressure Distribution in $\mathrm{Pa}$ : $391.5,324.9,258.2,191.5,124.9,58.20,-8.469$, 75.14, -141.8, -208.5, -275.1

Average Static Pressure Obtained, $\mathrm{P}=-187.10 \mathrm{~Pa}$.

Drag obtained, $\mathrm{F}=-179.10^{*} 900.05^{*} 10^{\wedge}-4$

$$
=-16.84 \mathrm{~N}
$$

From the pressure distribution, $(\partial \mathrm{P} / \partial \mathrm{x})$ is less than zero and so boundary layer separation does not exist at this particular velocity. The tables $3 \& 4$ shows that the average static pressure distribution and drag for both the headlight domes respectively.

For different orientations of the dome about $\mathrm{X}$-axis, the values for the pressure distribution and drag force of both the domes have shown in the above tables 3 and 4 for HERO HONDA PASSION PLUS and BAJAJ PULSAR respectively. BAJAJ PULSAR dome has low values of drag force comparatively with the HERO HONDA PASSION PLUS dome. Here, all the values are negative in sign convention. 
Table 3: For Hero Honda dome

\begin{tabular}{|c|c|c|c|c|c|}
\hline $\begin{array}{c}\text { ANGLE(IN } \\
\text { DEG })\end{array}$ & $\begin{array}{c}\text { PRESSURE(Pa) } \\
\text { DRAG(M) }\end{array}$ & $20 \mathrm{~m} / \mathrm{s}$ & $40 \mathrm{~m} / \mathrm{s}$ & $60 \mathrm{~m} / \mathrm{s}$ & $80 \mathrm{~m} / \mathrm{s}$ \\
\hline 0 & $\mathrm{P}$ & 210.12 & 838.38 & 1880.89 & 33338.92 \\
\hline & $\mathrm{F}$ & 18.91 & 75.45 & 169.2 & 300.50 \\
\hline $5(+Z)$ & $\mathrm{P}$ & 222.58 & 876.40 & 1972.44 & 3495.9 \\
\hline & $\mathrm{F}$ & 20.03 & 78.87 & 177.5 & 314.63 \\
\hline $10(+Z)$ & $\mathrm{P}$ & 223.31 & 884.28 & 1988.64 & 3531.33 \\
\hline & $\mathrm{F}$ & 20.09 & 79.58 & 178.97 & 317.81 \\
\hline $15(+Z)$ & $\mathrm{P}$ & 238.52 & 951.23 & 2132.72 & 3794.5 \\
\hline & $\mathrm{F}$ & 21.46 & 85.61 & 191.94 & 341.5 \\
\hline $5(-\mathrm{Z})$ & $\mathrm{P}$ & 192.47 & 770.32 & 1724.51 & 3072.72 \\
\hline & $\mathrm{F}$ & 17.32 & 69.32 & 155.20 & 276.54 \\
\hline $10(-\mathrm{Z})$ & $\mathrm{P}$ & 180.40 & 722.67 & 1627.81 & 2873.73 \\
\hline & $\mathrm{F}$ & 16.23 & 65.04 & 146.50 & 258.63 \\
\hline $15(-\mathrm{Z})$ & $\mathrm{P}$ & 174.61 & 689.84 & 1550.20 & 2753.62 \\
\hline & $\mathrm{F}$ & 15.71 & 62.08 & 139.51 & 247.82 \\
\hline
\end{tabular}

Table 4: For Bajaj Pulsar dome

\begin{tabular}{|c|c|c|c|c|c|}
\hline $\begin{array}{c}\text { ANGLE(NN } \\
\text { DEG) }\end{array}$ & $\begin{array}{c}\text { PRESSURE(Pa)\& } \\
\text { DRAG(I) }\end{array}$ & $20 \mathrm{~ms}$ & $40 \mathrm{~ms}$ & $60 \mathrm{~ms}$ & $80 \mathrm{~ms}$ \\
\hline & P & 143.82 & 576.31 & 1296.74 & 2306.17 \\
\hline & $\mathrm{F}$ & 12.94 & 51.86 & 11670 & 207.55 \\
\hline \multirow[t]{2}{*}{$S(+Z)$} & P & 158.39 & 626.12 & 1404.87 & 2496.54 \\
\hline & F & 14.25 & 56.35 & 126.43 & 224.68 \\
\hline \multirow[t]{2}{*}{$10(-2)$} & $P$ & 155.17 & 634.37 & 1425.85 & 2514.43 \\
\hline & F & 13.96 & 57.09 & 128.32 & 226.29 \\
\hline \multirow[t]{2}{*}{$15(-2)$} & $P$ & 169.95 & 678.25 & 1522.35 & 2694.11 \\
\hline & F & 15.29 & 61.04 & 137.01 & 242.46 \\
\hline \multirow[t]{2}{*}{$20(-Z)$} & P & 179.74 & 716.18 & 1600.34 & 2849.11 \\
\hline & F & 16.17 & 64.45 & 144.03 & 256.41 \\
\hline \multirow[t]{2}{*}{$25(+2)$} & $P$ & 200.21 & 801.07 & 1802.19 & 3209.68 \\
\hline & $F$ & 18.01 & 72.09 & 162.19 & 288.87 \\
\hline
\end{tabular}

\section{WIND TUNNEL}

Majority of experimental data needed in aerodynamics is generated using wind tunnels. Wind Tunnel is a device for producing airflow relative to the body under test. Wind tunnels provide uniform flow conditions in their test section. The figure 8 shows a suction type and open circuit low speed wind tunnel used to calculate the pressure distribution and drag force on the surface of the headlight dome which is to be placed in the test section of wind tunnel.

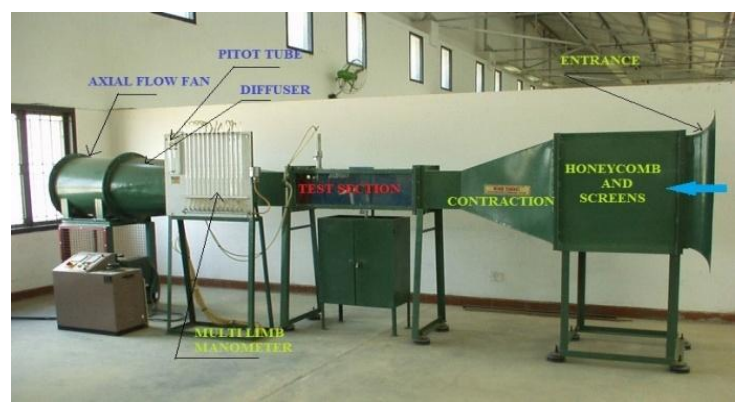

Fig. 8. Wind tunnel test rig.

After each run, the intake gets fresh air from the atmosphere. The effuser of the wind tunnel is the part of the wind tunnel from the beginning to the entry to the test section. The effuser makes the flow ready for the test section conditions. The test section provides the desired uniform flow conditions along and across the section. It is important that the test section conditions are controllable.

For HERO HONDA PASSION PLUS dome only, the validation has performed.

Wind tunnel specifications:

1. The total length of the wind tunnel is $5 \mathrm{~m}$.

2. The axial fan and the duct is $0.6 \mathrm{~m}$ long.

3. The maximu m height is about $2 \mathrm{~m}$.

4. Test section of $30 \mathrm{~cm} * 30 \mathrm{~cm}$ cross section and 100 cm length.

5. A xial flow fan with aluminum cast airfoil shaped blades driven by a $5 \mathrm{KW}$ AC motor mounted outside the duct.

Assume the loss factor $(\mathrm{K})$ is 0.11 because of the losses at inlet, outlet, test section, diffuser, obstructions, and change of cross sections.

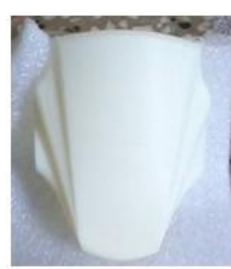

(a) Profile

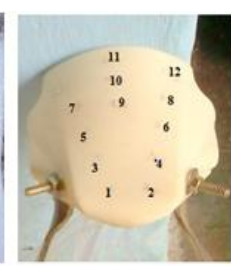

(b) Regions

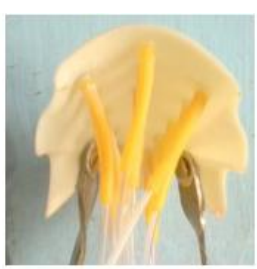

(c) Tapping arrangement
Fig. 9. Scale down profile of Hero Honda dome.

The figures 9 and 10 shows that the arrangement made to the model and fixing it in the test section of the wind tunnel. The velocity of the air flow will be measured from the pitot tube and the pressure distribution can be measured by the pressure taps connected to the multi limb manometer. 


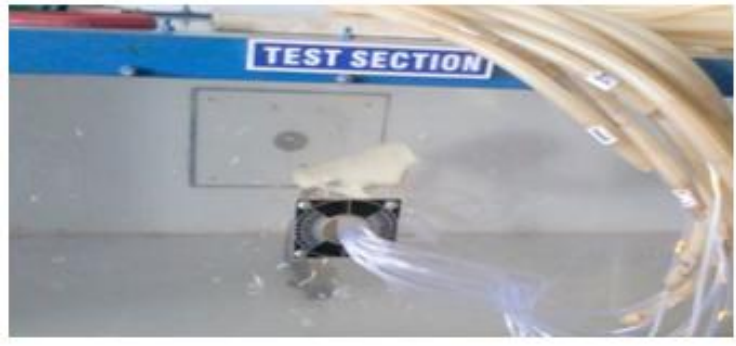

Fig. 10. Scale down profile in the Test section.

The points 1,2 are taken as region 1,3,4 are taken as region $2,5,9,6$ are taken as region $3,7,10,8$ are taken as region $\mathbf{4}, 11,12$ are taken as region $\mathbf{5}$.

At $1650 \mathrm{rpm}$, the following observations were made:

The difference of heads in the pitot tube $(\mathrm{q})=2.7 \mathrm{~cm}$ of water

In multi-limb manometer, scale readings are read as negative values.

Static pressure in 12 taps in cm of water as follows:

$-19.4,-19.8,-19.6,-20.3,-20.3,-20.6,-21.5,-20.7$, $20.7,-21.4,-22.5$.

Atmospheric pressure was $-17.1 \mathrm{~cm}$ of water.

Velocity,

$$
\begin{aligned}
V & =\sqrt{2 \times g \times q \times\left(\frac{\rho w}{\rho a}\right)} m / s \\
& =13 \sqrt{q} \\
& =21.36 \mathrm{~m} / \mathrm{s}
\end{aligned}
$$

Pressure Distribution in $\mathrm{Pa}$ :

$$
-211.50,-215.27,-223.37,-225.85,-236.86
$$

Average Static Pressure Obtained, $\mathrm{P}=-222.57 \mathrm{~Pa}$

Effective Area, $\mathrm{A}=900$ sq.cm

Drag, $\mathrm{F}=-222.57 * 900 * 10^{\wedge}-4=-20.03 \mathrm{~N}$

\section{VALIDATION \& CONCLUSIONS}

The table 5 shows that the comparison of HERO HONDA PASSION PLUS dome and BAJAJ PULSAR dome by using CFD simulation along with the experimental validation of HERO HONDA PASSION PLUS dome by using wind tunnel.

By observing the simulation results of both the domes, BAJAJ PULSAR dome has less drag compared to that of HERO HONDA PASSION PLUS dome neglecting sign conventions at a particular position and for a given speed. Therefore this profile may reduce the effect of turbulence and which in turn leads to the increase of fuel efficiency and also vehicle stability. By observing the validation results of HERO HONDA PASSION PLUS dome, the variance obtained is around $10 \%$ so that this type of validation can be done for various positions and at different velocities and it was found to be in acceptable range.

Fro $m$ the simulation, The minimu $m$ drag observed at $15^{\circ}(-Z), 10^{\circ}(-Z), 5^{\circ}(-Z), 0^{\circ}$ for HERO HONDA PASSION PLUS dome and at $0^{\circ}, 5^{\circ}(+Z), 10^{\circ}(+Z)$, $15^{\circ}(+Z)$ for BAJAJ PULSAR dome.
Table 5: Validation Results

\begin{tabular}{|c|c|c|c|c|}
\hline Parameter & $\begin{array}{c}\text { Simulation of } \\
\text { HERO } \\
\text { HONDA } \\
\text { dome }\end{array}$ & $\begin{array}{c}\text { Simulation of } \\
\text { BAJAJ } \\
\text { PULSAR } \\
\text { dome }\end{array}$ & $\begin{array}{c}\text { Experimentation of } \\
\text { HERO HONDA } \\
\text { dome }\end{array}$ & $\begin{array}{c}\text { Variance } \\
(\%)\end{array}$ \\
\hline $\begin{array}{c}\text { Average } \\
\text { static } \\
\text { pressure } \\
(\mathrm{Pa})\end{array}$ & -200.31 & -187.10 & -222.57 & 10 \\
\hline $\begin{array}{c}\text { Drag force } \\
(\mathrm{N})\end{array}$ & -18.04 & -16.84 & -20.03 & 9.93 \\
\hline
\end{tabular}

\section{SCOPE FOR EXTENSION}

Similar kind of experimentation can be performed for different profiles at different orientations and different air flow velocities. By changing the air flow velocity for a particular profile at different orientations or angular positions, average static pressure and drag force can be calculated and can be validated by conducting the experiments using the wind tunnel of different test section sizes. This study can be performed for any kind of headlight dome model or profile of a two-wheeler and which will helps us to reduce the effect of drag and increase the vehicle stability. We can also create a new headlight dome profile based on this computational analys is.

\section{REFERENCES}

[1]. R. B. Sharma, Ram Bansal, "CFD Simulation for Flow over Passenger Car Using Tail Plates for Aerodynamic Drag Reduction", vol.7, pp.28-35, 2013

[2]. R.A. Lukes, J.H. Hart, J. Potts, S.J. Haake, “A CFD analysis of flow around a disc", vol.72, pp.685-690, 2014

[3]. Yoakun wang, Zhiqiang wan, Chao yang, Yunzhen liu, "Static aeroelastic response analysis of air craft's based on CFD pressure distribution”, vol.3, pp.488-494, 2012

[4]. Li-Xin Guo, Yi-Min Zhang, Wei-Jun Shen, "Simulation analysis of Aerodynamics characteristics of different Two-Dimensional Automobile shapes", vol.6, pp.999-1005, 2011

[5]. Z.Q. Gu, L.H. Jiang, J. Wu, and G. Fang, “A computer simulation on 3-D outer flow field around a passenger car, "Automotive Engineering, vol. 22, pp. 296-298, 2000

[6]. Wind tunnel performance analysis report by Kailash Kotwani from Center for Aerospace System and Design Engineering, Department of Aerospace Engineering, Indian Institute of Technology, Bombay.

[7]. Ansys Workbench, Mesh, Fluent 14.5 Users Gu ide 